\title{
Gerotranscendence: Components and Spiritual Roots in the Second Half of Life
}

\author{
Sabrina Bruyneel, Alfons Marcoen, and Bart Soenens* \\ Katholieke Universiteit Leuven, Belgium
}

According to gerotranscendence theory (Tornstam, 1989), aging persons gradually develop "a shift in meta-perspective, from a materialistic and rational vision to a more cosmic and transcendent one". The present study examined the structure of the construct of gerotranscendence, age differences in gerotranscendence, and relations between gerotranscendence and culturally determined meaning in life and death factors, such as levels of spirituality, religious beliefs, moral judgment, and death attitudes. Participants were 467 adults between 17 and 91 years old. Factor analysis of the Gerotranscendence Scale yielded three subscales, Transcendent Connection, Anxiety and Uncertainty, and Active Involvement. Transcendent Connection - the core component of gerotranscendence - was only weakly related to age. However, Transcendent Connection was positively related to spiritual views and practices, relativistic orientation to religious beliefs, moral consistency, higher stages of moral thinking, and negatively related to avoidance of death. Patterns of correlations with the scores on the other two scales were also explored. Together, the findings suggested that individuals' development with regard to issues of spirituality, religiosity, morality, and death attitudes is more fundamental for their development toward "gero"-transcendence than the natural process of aging.

\footnotetext{
*Correspondence concerning this article should be addressed to Sabrina Bruyneel, Onderzoekscentrum Marketing, K.U.Leuven, Naamsestraat 69, B-3000 Leuven, Belgium. E-mail:

Sabrina.Bruyneel@econ.kuleuven.be, or Alfons Marcoen, Centrum voor Ontwikkelingspsychologie, K.U.Leuven, Tiensestraat 102, B-3000 Leuven, Belgium. E-mail: Alfons.Marcoen@psy.kuleuven.be, or Bart Soenens, Centrum voor Ontwikkelingspsychologie, K.U.Leuven, Tiensestraat 102, B-3000 Leuven, Belgium. E-mail: Bart.Soenens@psy.kuleuven.be .
} 


\section{Introduction}

During the late eighties and early nineties, scholars observed a number of contradictory findings in social gerontology research. Because of these troubling findings, some gerontologists started to challenge the assumption that old age represents the continuation of midlife patterns and values of life, and rather proposed that old age reflects a development into a qualitatively different state of being (e.g., Tornstam, 1992). Tornstam $(1989,1994)$ developed the theory of gerotranscendence, which basically assumes that development into old age might lead gradually to a stage with its own specific quality of life. In the present paper, we first present an overview of gerotranscendence theory and the empirical research conducted within this perspective. Next, three research questions dealing with some of the core assumptions of gerotranscendence theory will be outlined.

\section{Tornstam's Theory of Gerotranscendence}

In the history of gerontology, Cumming and Henry's disengagement theory has been very influential (Cumming, 1963; Cumming \& Henry, 1961; Cumming \& Newell, 1960). This theory stated that aging individuals experience an inherent tendency to withdraw from society and to turn inwards, that is, to disengage. This individual disengagement was theorized to be both social and psychological. Social disengagement referred to a diminished participation in social roles, whereas psychological disengagement referred to a reduced interest and involvement in other people and society. At the same time, society was also assumed to display a tendency to reject aging persons. Both for the elderly individual and society, this two-way process was believed to be inevitable, functional, and associated with satisfaction and inner harmony. Hence, stimulating elderly people in some way to violate the natural process of disengagement was believed to lead to a decrease in life satisfaction. However, many gerontologists disagreed with the theory of disengagement, which received its coup de grace with the introduction of Kuypers and Bengtson's social break-down syndrome (Kuypers \& Bengtson, 1973). Almost twenty years later however, Tornstam revised the original disengagement theory (Tornstam, 1989, 1994).

Tornstam $(1989,1994)$ argued that what gerontologists described in negative terms and called 'disengagement' is in reality often a positive development towards 
gerotranscendence, "a shift in meta-perspective from a materialistic and rational view to a more cosmic and transcendent one, normally followed by an increase in life satisfaction" (Tornstam, 1989, p. 60). In principle, the general tendency towards gerotranscendence is universal and culture free. Moreover, the process is continuous but can be accelerated or obstructed by specific cultural factors. This shift in metaperspective may include an increasing feeling of a cosmic communion with the spirit of the universe, a redefinition of the perception of time, space and objects, a redefinition of the perception of life and death and a decrease in the fear of death, an increased feeling of affinity with past and coming generations, a decrease in interest in superfluous social interaction and material things, a decrease in self-centeredness, and more time spent in meditation. Tornstam $(1989,1994)$ also pointed out some resemblances between the concept of gerotranscendence and other theoretical concepts such as Jung's collective unconscious (Jung, 1968), Erikson's model of ego development (Erikson, 1950, 1982, 1986), and Gutmann's concept of passive and magical mastery (Gutmann, 1976).

In a review of postwar psychological theories of aging, Schroots (1996) mentioned gerotranscendence as an important theory introduced between 1980 and 1990. At that time, the theory was lacking of extensive empirical evidence. Nevertheless, as it integrated several classical and modern theories of aging, it was said to be very promising (Schroots, 1996). Soon the theory inspired a lot of empirical research and became an influential paradigm among both theorists and clinical practitioners, particularly within Scandinavian gerontology (Jönson \& Magnusson, 2001). According to Jönson and Magnussen (2001), the increasing influence of gerotranscendence theory was due to its offering a solution to one of the fundamental issues of modern aging, namely the identification of a positive old age that does not deny decay and dependence.

Based on several qualitative and quantitative studies, Tornstam (1996a, 1996b, 1997a, 1997b, 1997c, 1999a, 1999b; Tornstam \& Törnqvist, 2000) further elaborated the theory by providing a more comprehensive and detailed description of the changes people experience when moving towards gerotranscendence. More specifically, a distinction was made between three so-called dimensions of gerotranscendence: the cosmic level, the self, and social and individual relations. The first dimension, the cosmic level of gerotranscendence, appeared to encompass changes in the definition of time and space, increased feelings of connection to earlier generations, 
disappearing fear of death and new comprehension of life and death, acceptance of the mystery dimension in life, and rejoicing in both grand events and subtle experiences. The second gerotranscendence dimension, the level of the self, was hypothesized to encompass discovery of hidden aspects of the self, removal of the self from the centre of one's universe, continuation of care of the body without obsession with it, a shift from egoism to altruism, experience of return to and transfiguration of childhood, and realization that the pieces of life's jigsaw puzzle form a wholeness. Finally, the third gerotranscendence dimension, the level of social and individual relations, appeared to encompass decreasing interest in superficial relations and increasing need for solitude, understanding of the difference between self and role - possibly accompanied by an urge to abandon roles, maturity-enhancing innocence, understanding of the petrifying gravity of wealth and the freedom of asceticism, difficulty in separating right from wrong, and withholding from judgments and giving advice.

In addition to the new theoretical insights provided by gerotranscendence theory, the theory appeared to have substantial practical implications (Tornstam, 1996a; Tornstam \& Törnqvist, 2000; Wadensten \& Carlsson, 2001). In fact, Tornstam (1996a) introduced his theory to a group of staff working with the elderly. He observed that the majority of the staff members understood the theory and thought that the theory corresponded to the reality they were familiar with. In addition, about half of the staff members contended to have gained new insights on certain care recipients and to have experienced reduced feelings of guilt about inadequacy at work after presentation of the theory. Moreover, the theory appeared to have positively affected a minority of the staff's outlook on their own aging and old age and their behavior in relation to the care recipients. Hence, the theory of gerotranscendence was recognized as a theory describing relevant parts of the reality staff members meet in their work with elderly care recipients (Tornstam, 1996a).

Tornstam and Törnqvist (2000) found that staff members working in a nursing home for the elderly noticed the transcendence of the time borders between past and present, the increasing need for solitude, the rejoicing in small events, and the modern asceticism, but interpreted these behaviors as being negative. In addition, staff members noticed the rediscovery of the child within, the connection to earlier and future generations, and the sense of ego-integrity, and interpreted these behaviors as being positive. However, only a minority of the staff members noticed signs of selftranscendence, disappearing fear of death, self-confrontation, body transcendence, and 
everyday wisdom. Those behaviors were associated with both positive and negative meanings. The authors concluded that more theoretical knowledge about alternative frames of references would lead to an increase in the quality of the care currently offered to elderly individuals (Tornstam \& Törnqvist, 2000).

Wadensten and Carlsson (2001) also observed that the theory of gerotranscendence might be a useful frame of reference for staff members working with elderly people. Hence, they (Wadensten \& Carlsson, 2001, 2003) developed a number of guidelines derived from gerotranscendence theory on how to relate to and treat older people. For instance, caregivers were advised to accept the components of signs of gerotranscendence as normal signs of aging, reduce preoccupation with the body, allow an alternative definition of time, allow thoughts and conversations on death, choose topics of conversation that facilitate and stimulate older people's personal growth, create and introduce other types of activities, and encourage and facilitate quiet and peaceful moments of rest. According to the authors (Wadensten \& Carlsson, 2003), such guidelines might be used to promote a development toward gerotranscendence.

\section{Empirical Research within Gerotranscendence Theory}

For the measurement of gerotranscendence, Tornstam (1994, 1997a) constructed two gerotranscendence scales. The first scale consisted of a series of ten items that were mainly selected through qualitative interviews and tests with elderly people (Tornstam, 1994). An exploratory factor analysis identified two theoretical dimensions of gerotranscendence, namely, cosmic transcendence and ego transcendence. The first dimension defined a type of transcendence connected with changes in the perception or definition of time, space, life and death, whereas the second dimension was connected with changes in the perception of the self and relations to others. All items were formulated retrospectively. Therefore, this scale was to be used in a population of exclusively older people (Tornstam, 1994). The second scale consisted of a series of 25 statements that were more directly framed in accordance with theoretical dimensions of gerotranscendence (Tornstam, 1997a). An exploratory factor analysis identified the three theoretical dimensions of gerotranscendence described in the preceding paragraphs, cosmic transcendence, coherence, and solitude. The cosmic dimension referred to the transcendence of space, time, and objects. Coherence corresponded to one of the changes related to the 
self (i.e., ego-integrity). Solitude was connected with the changed meaning and importance of social and individual relationships. Because statements were worded in the present tense, this scale could be used in research including participants with a wide age range (Tornstam, 1997a). Using both scales, several variables such as selfinitiated social activity, offensive and multi-coping, life satisfaction (Tornstam, 1994), age (Tornstam, 1997a), and functions of reminiscence (Tornstam, 1999a) have been shown to correlate positively with gerotranscendence. In contrast, variables such as fear of death (Tornstam, 1997a) were found to correlate negatively with gerotranscendence. In addition, women and people who experienced one or more life crises were found to obtain high scores on the gerotranscendence subscales (Tornstam, 1997a, 1997c).

Braam and colleagues (Braam, Deeg, van Tilburg, Beekman, \& van Tilburg, 1998) developed a Dutch translation of Tornstam's ten-item gerotranscendence scale . A factor analysis replicated the distinction between the two factors identified by Tornstam. However, the strength of the associations between gerotranscendence and other psychosocial variables (i.e., positive associations with age, life crises, and depressive symptoms versus negative associations with social activity) was modest, and the variance explained was small. More recently, Raes and Marcoen (2001) additionally developed a Dutch version of Tornstam's 25-item gerotranscendence scale. An exploratory factor analysis yielded three factors that were reconcilable to the theory of gerotranscendence. Theoretically expected relations between gerotranscendence and several psychosocial variables emerged (i.e., positive associations between gerotranscendence and the variables age, life crises, positive attitudes towards death, and religious dimensions).

\section{The Gerotranscendence Theory under Critique}

Although generally promising, an important criticism on research on the theory of gerotranscendence is that studies have failed to provide systematic evidence for gerotranscendent wisdom as a feature that is exclusively typical for old age or, in other words, as a feature that manifests itself qualitatively different in old age compared to other stages of life (Jönson \& Magnusson, 2001). Recently, researchers have shown that spiritual ways of thinking rather than aging per se may stir the development of certain transcendent views (Ahmadi, 1998, 2000; Ahmadi Lewin, 2001; Ahmadi Lewin \& Thomas, 2000; Thomas, 2001). One particular spiritual way 
of thinking and living is Sufism, which is the generally accepted name for Islamic mysticism. Sufism might be regarded as "an intuitive way of comprehending the world, an epistemological method for interpreting it, and a technique for spiritually mastering it" (Ahmadi, 1998, p. 191). In a qualitative study with Iranian Sufis, Ahmadi (1998) found that internalisation of Sufi ideas did alter life conditions such that Sufi interviewees developed many of the so-called dimensions of gerotranscendence before entering into old age (i.e., redefinition of reality similar to transcending borders of time and space, absence of fear of death, self-confrontation and self-transcendence, need for solitude, change in meaning and importance of relationships, modern asceticism, and transcendent wisdom). It was concluded that the study supported the assumption that the development of gerotranscendence is not only a consequence of aging as such, but also of culture and of the development of a 'way of thinking' (Ahmadi, 1998).

In a similar vein, Ahmadi (2000) found that spiritual development can be essential for nurturing certain qualities of gerotranscendence (i.e., self-confrontation, selftranscendence, changes in meaning and importance of relationships, and transcendent wisdom), but that the existential integrity that old age can offer may make possible a complete achievement of those qualities. In another study it was found that some very religious Turkish participants were almost totally lacking in gerotranscendence (Ahmadi Lewin \& Thomas, 2000; Thomas, 2001). However, results of this study also showed that a positive relationship between gerotranscendence and life satisfaction was more evident among religious rather than non-religious Turkish participants. The latter finding also held true for Iranian participants. The authors concluded that there can be said to be a fertile soil for development towards gerotranscendence among individuals in a cultural setting where mystical-type ideas are integrated into people's ways of thinking. This should be the case irrespective of religiosity (Ahmadi Lewin, 2001).

\section{The Present Research}

The major aim of the present investigation was to gain more insight in the components of gerotranscendence, its age-relatedness, and possible roots in religious and spiritual outlook on life variables. Is gerotranscendence indeed a highly agerelated phenomenon? Or do culturally determined meaning in life and death factors, originating from within spirituality, religion and morality, relate more strongly to 
gerotranscendence components than age? Drawing on theoretical considerations and results of empirical investigations (Raes \& Marcoen, 2001; Tornstam, 1989), we expected to find a negative correlation between gerotranscendence and feelings of fear of death, and high degrees of gerotranscendence in persons who experience the presence of a transcendental and symbolical dimension in their faith. Given the recent findings on the importance of spirituality for the development towards a transcendent outlook on life (Ahmadi, 1998, 2000; Ahmadi Lewin, 2001; Ahmadi Lewin \& Thomas, 2000; Thomas, 2001), we also expected a positive relation between spiritual attitudes and gerotranscendence. Finally, the level of moral development was included in the present study. Building on the theoretical resemblance between the cosmic dimension of gerotranscendence and Kohlberg's sixth and seventh stage of moral development (Raes, 2000), participants' moral consistency and level of moral judgment were hypothesized to be positively related to gerotranscendence.

\section{Method}

\section{Participants}

The present study was conducted in Flanders, the Dutch speaking part of Belgium. The mean age of the 467 participants ( 297 women) was 45.84 years $(S D=15.35)$, ranging between 17 and 91 years. The majority of the respondents was married (69\%), had children (75\%), and was professionally active (58\%). A substantial part of the respondents was catholic (42\%) or called themselves a Christian (39\%). Many participants considered their outlook on life as not particularly weak or strong (47\%), nor particularly important (38\%). However, for some respondents it was strong (35\%) and it did matter a lot (37\%).

Participants were recruited by means of a snowball sampling procedure. They received booklets containing the scales and questionnaires and some basic information on each of them. The scales questionnaires appeared in a fixed order. An effort was made to alternate more difficult scales with more easy ones. Respondents were free to fill out the booklets at their own pace and in private.

\section{Materials}

A set of biographical questions probed into participants' personal lives. Respondents were asked to answer questions regarding their age, gender, marital status, family situation, professional situation, and outlook on life. 
A Dutch version (Raes \& Marcoen, 2001) of the Gerotranscendence Scale (Tornstam, 1997a) consisted of 25 items assessing respondents' current state of gerotranscendence (see Table 1). For each item, answers were given on a six-point scale ranging from not applicable to me at all (0) to totally applicable to me (5).

The Death Attitude Profile Revised (DAP-R, Wong, Reker, \& Gesser, 1994) consisted of 32 items assessing respondents' attitude towards death. Participants were asked to indicate the extent to which they agreed with each statement. Answers were given on a seven-point scale ranging from totally disagree (-3) to totally agree (3). The scale contains five subscales that each relate to one of five different attitudes towards death: Avoidance of death (trying very hard not to be confronted with death), Fear of death (having negative thoughts and feelings about death), Approaching acceptance of death (accepting death because of the belief in a happy afterlife), Escaping acceptance of death (seeing death as a welcome alternative for a life filled with misery and pain), and finally, Neutral acceptance of death (seeing death as a natural part of life).

The Post-Critical Belief Scale (Duriez, Fontaine, \& Hutsebaut, 2000) consisted of 33 items assessing participants' attitude towards religion. For each item, respondents were asked to indicate the extent to which their own attitude corresponded to the one advocated in the statement. Answers were given on a seven-point scale ranging from totally disagree (-3) to totally agree (3). The scale was known to contain four subscales that each relate to one of four different attitudes towards religion and that emerge from crossing two bipolar dimensions (i.e., inclusion versus exclusion of transcendence and literal versus symbolic interpretation of religion). More specifically, the combination of inclusion of transcendence and literal interpretation of religion leads to Orthodoxy. Orthodoxy represents a position in which the literal existence of a religious reality is affirmed. The combination of exclusion of transcendence and literal interpretation of religion leads to External critique. Similar to Orthodoxy, External critique assumes that religious language is to be taken literally. However, the transcendent reality is rejected rather than affirmed. The combination of inclusion of transcendence and symbolic interpretation of religion leads to Second naiveté. Second naiveté represents a position in which the religious reality is affirmed based on a symbolic approach of religion. Finally, the combination of exclusion of transcendence and symbolic interpretation of religion leads to Relativism. Relativism represents a position in which the existence of a religious 
reality is rejected and in which a privileged perspective of the true meaning of religion is claimed.

Spiritual orientation was assessed using a short and modified version of the Spiritual Orientation Inventory (Elkins, Hedstrom, Hughes, Leaf, \& Saunders, 1982). It consisted of 9 items assessing respondents' spiritual beliefs. Each item was taken from one of the 9 subscales that the original scale was composed of. Answers were given on a five-point scale ranging from totally disagree (-2) to totally agree (2). In addition, we added descriptions of 8 spiritual activities and asked participants to indicate on a four-point scale how often they engaged in each activity, ranging from several times a day to several times a week (4) to once a year or less (1). Finally, one item probed into respondents' subjective degree of spiritual orientation. Answers ranged from strong (1) to not at all (4).

The Moral Judgment Test (Duriez \& De Marez, 2000; Duriez \& Soenens, in press) consisted of two moral dilemmas. For each dilemma, respondents were asked to indicate the extent to which they approved of the behavior of the story's main character. They could do so on a nine-point scale ranging from this behavior is very wrong (-4) to this behavior is very right (4). Subsequently, for each dilemma, respondents were provided with six reasons as to why the main character's behavior might be perceived as being wrong, and with six reasons as to why the main character's behavior might be perceived as being right. Each reason corresponded to one particular stage in Kohlberg's theory of moral development (Kohlberg, 1984). Participants could indicate the extent to which they thought each reason was acceptable on a nine-point scale ranging from this reason is totally unacceptable (-4) to this reason is totally acceptable (4).

The most important index that is retained for the Moral Judgment Test, is moral consistency. It indicates the extent to which respondents are consistent in evaluating the reasons as to why the main character's behavior might be perceived as being right or wrong. Respondents with a high degree of moral consistency will value all statements referring to one particular stage of moral development alike, regardless of whether they actually agree with these statements or not. The Moral Judgment Test also allows one to assess respondents' current stage of moral development. Each stage of moral development is represented by four statements. Summing up respondents' scores on these four statements provides us with a score for each of the 
six stages of moral development. The stage that respondents obtain the highest score on corresponds to their current stage of moral development.

\section{Results}

\section{Factor Structure of Scales}

Gerotranscendence scale. An iterative principal component analysis on the Gerotranscendence Scale yielded three factors and corresponding subscales that were subjected to varimax rotation (see Table 1) (Table 1 about here). Eigenvalues were $4.10,2.17$, and 1.97 , respectively. Items were considered to be part of a factor in case they loaded at least .30 on that particular factor and less than .30 on any other factor. The factors collectively explained $32.97 \%$ of the variance. The factor Transcendent Connection (TC) consisted of nine items $(\alpha=.73)$ referring to a feeling of receptive connectedness with the universe, life, one's self and characteristics of the other gender in oneself, unknown people, and previous generations. On average, respondents indicated that the Transcendent connection statements were rather applicable to them $(M=25.11, S D=6.70)$. The second factor Anxiety and Uncertainty (AU) contained seven items $(\alpha=.60)$ representing experiences of death, anxiety, uncertainty, chaos and confusion. Respondents indicated that the Anxiety and uncertainty statements were (rather) not applicable to them $(M=12.54, S D=5.15)$. Finally, the factor Active Involvement $(\mathrm{AI})$ consisted of five items $(\alpha=.51)$ and seemed to refer to an active preoccupation with and involvement in daily activities. Respondents thought the Active Involvement statements to be rather applicable to them $(M=15.10, S D=$ 3.55). Although the three subscales were positively correlated $(r(\mathrm{TC}, \mathrm{AU})=.23, p<$ $.001 ; r(\mathrm{TC}, \mathrm{AI})=.18, p<.001 ; r(\mathrm{AU}, \mathrm{AI})=.13, p<.01)$, intercorrelations were low, indicating that the three factors could be clearly distinguished.

Other scales. Factor analyses were also performed on the other questionnaires. Drawing on the results of those analyses, most scales were divided into subscales. Cronbach's alpha coefficients were satisfactory, ranging from .71 to .91 . Table 2 provides an overview of the means and standard deviations of the scale scores (Table 2 about here). Overall, respondents obtained higher scores for positive attitudes towards death (i.e., neutral acceptance and approaching acceptance of death) than for negative attitudes towards death (i.e., avoidance, fear, and escaping acceptance of death). In addition, respondents obtained higher scores for attitudes of symbolic 
interpretation of religion (i.e., relativism and second naiveté) than for attitudes of literal interpretation of religion (i.e., orthodoxy and external critique). Respondents also tended to agree with statements regarding spiritual beliefs, but subjectively judged themselves to be not very spiritually oriented. They did not engage in spiritual practices very often either. Finally, respondents scored low on moral consistency. Statements referring to the fifth stage of moral development were agreed with most often.

\section{Correlates of Gerotranscendence}

The correlations between the scores on the three gerotranscendence scales and age, and the different religious-spiritual variables, are presented in Table 3 (Table 3 about here). Different patterns of correlations emerged. The older respondents were, the lower they scored on Transcendent Connection and Anxiety and Uncertainty, but the higher they scored on Active Involvement. A visual inspection of our data suggested that the association between age and Transcendent Connection might be curvilinear in nature, which was substantiated by formal analyses $(\beta=-.11, t=-2.29, p<.05)$. From the comparison between different age groups it appeared that respondents in the age group 40- 49 obtained the highest scores on Transcendent Connection $(M=$ 27.01), significantly higher than the scores of the respondents aged 60-69 and 70 years and older $(M=23.49$ and 22.49), and the 30-39 year olds $(M=24.40)$. No age group differences were observed on the Anxiety and Uncertainty scale. On Active Involvement the 60-69 year olds scored highest $(M=16.54)$. The 30-39 year olds only scored significantly lower $(M=14.18)$.

Transcendent Connection was positively related to positive attitudes towards death (i.e., neutral and approaching acceptance of death), attitudes towards religion implying symbolic interpretations (i.e., relativism and second naiveté), spiritual beliefs, spiritual practices, moral consistency, and stage five and six moral thinking, and negatively related to negative attitudes towards death (i.e., avoidance of death), literal interpretations of religion implying attitudes (i.e., orthodoxy and external critique), and lower stages of moral thinking (i.e., stages one, two and three). Anxiety and Uncertainty was positively related to all attitudes towards death except for neutral acceptance, to which it was unrelated. It was also positively related to the second naiveté type of believing, spiritual beliefs, and stage four moral thinking. Active Involvement was positively related to both negative (i.e., avoidance and fear of 
death) and positive attitudes towards death (i.e., approaching acceptance of death), interpretations of religion that include the transcendental dimension (i.e., orthodoxy and second naiveté), spiritual beliefs, and stage three moral thinking, and negatively related to neutral acceptance of death and external critique.

Finally, we conducted separate multiple regressions on the scores on the gerotranscendence subscales. The other variables previously discussed served as independent variables (see Table 4) (Table 4 about here). Transcendent Connection was positively predicted by spiritual beliefs, spiritual practices, and relativistic orientation to religious beliefs, and negatively by avoidance of death. The model explained $30 \%$ of the variance. Anxiety and Uncertainty was in a positive direction predicted by death anxiety, approaching acceptance of death, and spiritual beliefs, and in a negative direction by age. The variance explained was $21 \%$. Active Involvement was positively related to stage three moral thinking and death anxiety, and negatively to criticism on religious beliefs. The model explained $13 \%$ of the variance.

\section{Discussion}

Although the factor structure of the gerotranscendence scale obtained in the present investigation does not really reflect the three dimensions originally proposed by Tornstam (1997a), our findings do replicate earlier findings obtained by Raes and Marcoen (2001) in a sample of 45-99 years old adults. Comparable factors were obtained, although some items migrated to other factors. The three subscales were labelled Transcendent Connection, Anxiety and Uncertainty, and Active Involvement. From a visual inspection of the items it becomes clear that the Transcendent Connection scale undoubtedly fully represents a state of gerotranscendence as defined in Tornstam's theory. This is less obvious, however, with regard to the other two scales. The items of the Anxiety and Uncertainty scale refer to a state of existential alienation, estrangement with the self, attachment to the material world, and death anxiety. The Active Involvement items reflect the need to be continuously involved in work, activities and things happening, preferably with others. Maybe the Transcendent Connection scale measures the contemplative side of the state of gerotranscendence whereas the Active Involvement scale assesses the inclination to active ego-involvement that may or may not go together with the more contemplative side of relatedness to the world. 
Correlations between the scales were positive but low. Whereas the internal consistency of the Transcendent Connection scale was acceptable, the internal consistency of the Anxiety and Uncertainty and the Active Involvement scales was rather low. These results induce concern about the interpretation of the latter two factors in the light of the gerotranscendence theory. In addition, because the items defining the Transcendent Connection scale most directly reflect the construct of gerotranscendence, the results obtained with the Transcendent Connection scale deserve primary attention.

We expected to find that culturally determined meaning in life and death factors originating from within spirituality, religion and morality would be stronger correlates of the "gero"-transcendence components than age. We found a negative correlation between age and Transcendent Connection. In his own studies, Tornstam (1997b) found positive and negative, as well as zero correlations between gerotranscendence and age. These differences might be related to differences between the age ranges of the samples. In the present study signs of gerotranscendence emerged especially in 40-49 years old adults. May be the items of the Transcendent Connection scale reflect the ego-transcendence which characterizes the mid-life experience and transition, originally described by Jung (1968). These results suggest a complex relation between gerotranscendence (as measured with the Transcendent Connection scale) and age, and may induce criticism on labelling the tendency towards transcendence as "gero"-transcendence.

Interesting results were obtained for the variables attitudes towards death, religion, spirituality, and moral development. As expected, higher scores on Transcendent Connection were associated with a less negative attitude towards death. Partly in line with predictions, the tendency to think thoroughly about acceptance or rejection of the (symbolically interpreted) religious believes one is socialized into, correlates positively with Transcendent Connection, whereas the inclination to accepting or rejecting uncritically these literally interpreted believes, correlates negatively with Transcendent Connection. This implies that a symbolic approach of religion creates a state of being that is reflected in the statements of the Transcendent Connection scale. This interpretation meshes with other findings in the present study. The hypothesis that both spiritual practices and spiritual beliefs are positively correlated to Transcendent Connection is confirmed, and the regression on the scores on Transcendent Connection yielded the variables spiritual beliefs and spiritual practices 
as the two most important predictors of Transcendent Connection. All these observations are in support of the assertions of Ahmadi (1998).

Finally, moral consistency correlates positively with Transcendent Connection. The same holds true for the highest two stages of moral development, whereas the lower stages of moral development are negatively correlated with Transcendent Connection. These results add to the elucidation of the gerotranscendence concept in connection to the development of moral judgment. As "a late stage in a natural process toward maturation and wisdom" (Tornstam, 1996b, p. 38) the state of gerotranscendence seems to imply an inclination to post-conventional moral reasoning (Kohlberg, 1984).

The strongest correlations with Anxiety and Uncertainty were found among the death attitude variables. Especially fear of death is a strong predictor. In view of these correlations and similar positive correlations with a few religious-spiritual variables and negative correlations with age it might be meaningful to interpret the Anxiety and Uncertainty scale as referring to the awareness of the finitude of life. Given the positive correlations between Transcendent Connection and Anxiety and Uncertainty these observations suggest a question about the incompatibility between gerotranscendence and death anxiety. Would it not be possible that in the early stages of its development - and not in its final state - gerotranscendence goes together with a pronounced awareness of and preoccupation with the finitude of life?

The patterns of Active Involvement correlates and predictors suggest several sources of engagement of the respondents with themselves and others in social and professional activities in order to meet the expectations of their fellow men (stage three moral judgment) and their (post-critically) accepted religious beliefs and spirituality, in the context of the awareness of the finitude of life (death attitudes, and especially fear of death).

In conclusion, our hypotheses regarding the connection between gerotranscendence and spirituality, religion and moral development variables were generally confirmed. This finding echoes Tornstam's (1994) statement that "depending on the definition of 'religion', the theory of gero-transcendence may or may be not regarded as a theory of religious development" (p. 203). We believe that development into qualitatively higher levels of spiritual, religious and moral thinking and living might be important prerequisites for, or components of gerotranscendence. Future research is needed to 
elucidate the concept of gerotranscendence in relation to other concepts that indicate end states of advanced human development.

We agree with Tornstam (1994) when he, in explaining his finding of a lack of correlation between chronological age and the degree of gerotranscendence, assumes that progress toward gerotranscendence will not necessarily be dependent on age per se, because it is a developmental process primarily connected with living, having various experiences in and learning from life. However, we do not agree with Tornstam (1994) when he, although admitting that progress toward gerotranscendence will only be loosely connected with chronological age, states that the highest degree of gerotranscendence will only be found in the elderly. In fact, we found that younger people can display high degrees of gerotranscendence as well. This result reminds us of analogous observations in wisdom research (Baltes \& Smith, 1990). Wisdom, as an expert knowledge system concerning the fundamental pragmatics of life, is not the monopoly of elderly people, younger adults can be wise as well, especially if their life circumstances and the nature of their professional activities confront them with "wisdom-salient life experiences, including professional skills and opportunities for practice and being monitored" (Baltes \& Freund, 2003, p. 254; Baltes, Staudinger, Maercker, \& Smith, 1995; Smith, Staudinger, \& Baltes, 1994). Wisdom may continue to evolve into old age under the influence of new experiences, as well as never take off because of obstacles in the person and his or her environment. One can imagine that gerotranscendence with its core experience of ego transcendence, or being embedded in a transpersonal, transgenerational and time transgressing reality transcendent connection, constitutes the wisdom-related positive side of development and aging in the second half of life. The relationships between gerotranscendence and other - in adulthood and old age not strictly age-related - developmental end-states such as wisdom, post-conventional morality (Kohlberg, 1984), ego-integrity (Erikson, 1950, 1982, 1986), universalizing faith (Fowler, 1981), and post-critical belief (Hutsebaut, 1996), deserve further attention of researchers in different domains which until now developed relatively apart. 


\section{References}

Ahmadi, F. (1998). Sufism and gerotranscendence: The impact of way of thinking, culture and aging on spiritual maturity. Journal of Aging and Identity, 3, 189-211. Ahmadi, F. (2000). Reflections on spiritual maturity and gerotranscendence: dialogues with two Sufis. Journal of Religious Gerontology, 11, 43-74. Ahmadi Lewin, F. (2001). Gerotranscendence and different cultural settings. Aging and Society, 21, 395-415.

Ahmadi Lewin, F., \& Thomas, L. E. (2000). Gerotranscendence and life satisfaction: studies of religious and secular Iranians and Turks. Journal of Religious Gerontology, $12,17-41$.

Baltes, P. P., \& Freund, A. M. (2003). The intermarriage of wisdom and selective optimization with compensation: Two meta-heuristics guiding the conduct of life. In C. L. M. Keyes \& J. Haidt (Eds.), Flourishing: Positive psychology and the life welllived (pp. 249-273). Washington: American Psychological Association.

Baltes, P. B., Staudinger, U. M., Maercker, A., \& Smith, J. (1995). People nominated as wise: A comparative study of wisdom-related knowledge. Psychology and Aging, $10,155-166$.

Braam, A. W., Deeg, D. J. H., van Tilburg, T. G., Beekman, A. T. F., \& van Tilburg, W. (1998). Gerotranscendence as a life cycle perspective: A first empirical approach among older adults in the Netherlands. Tijdschrift voor Gerontologie en Geriatrie, $29,24-32$.

Cumming, E. (1963). Further thoughts on the theory of disengagement. UNESCO International Science Journal, 15, 377-393.

Cumming, E., \& Henry, W. (1961). Growing old: The process of disengagement. New York: Basic Books.

Cumming, E., \& Newell, D. S. (1960). Disengagement: A tentative theory of aging. Sociometry, 23, 23-24.

Duriez, B., \& De Marez, P. (2000). Voorstelling en validering van de Morele Oordeel Test (MOT), de Nederlandstalige versie van de Moral Judgment Test (MJT) [Presentation and validation of the Dutch version of the Moral Judgment Test (MJT)]. Unpublished manuscript, University of Leuven, Department of psychology, Leuven, Belgium.

Duriez, B., Fontaine, J. R, \& Hutsebaut, D. (2000). A further elaboration of the post- 
critical belief scale: Evidence for the existence of four different approaches to religion in Flanders - Belgium. Psychologica Belgica, 40, 153-181.

Duriez, B., \& Soenens, B. (in press). Religiosity, moral attitudes and moral competence: A critical investigation of the religiosity - morality relation.

International Journal of Behavioral Development.

Elkins, D. N., Hedstrom, L. J., Hughes, L. L., Leaf, J. A., \& Saunders, C. (1988). Toward a humanistic-phenomenological spirituality. Definition, description, and measurement. Journal of Humanistic Psychology, 28 , 5-18.

Erikson, E. H. (1950). Childhood and society. New York: Norton.

Erikson, E. H. (1982). The life cycle completed - A review. New York: Norton.

Erikson, E. H. (1986). Vital involvement in old age. New York: Norton.

Fowler, J. W. (1976). Stages of faith: The psychology of human development and the quest for meaning. Cambridge: Harper \& Row.

Gutman, D. (1976). Alternatives to disengagement: The old men of the highland Druze. In J. F. Gubrium (Ed.), Time, roles and self in old age. New York: Human Sciences Press.

Hutsebaut, D. (1996). Post-critical belief: A new approach to the religious attitude problem. Journal of Empirical Theology, 9, 48-66.

Jönson, H., \& Magnusson, J. A. (2001). Gerotranscendence and the re-enchantment of aging. Journal of Aging Studies, 15, 318-333.

Jung, C. G. (1968). Die Lebenswende. In Jung C. G., Gesammelte Werke 8 (pp. 443460). Zürich: Rascher.

Kohlberg, L. (1984). The psychology of moral development. San Francisco: Harper \& Row.

Kuypers, J. A., \& Bengtson, V. L. (1973). Social breakdown and competence. A model of normal aging. Human Development, 16, 181-201.

Raes, F. (2000). De gerotranscendentietheorie van Lars Tornstam: Situering en empirische exploratie [Lars Tornstam's theory of gerotranscendence. Empirical exploration]. Unpublished master's thesis, University of Leuven, Department of psychology, Leuven, Belgium.

Raes, F., \& Marcoen, A. (2001). Gerotranscendence in the second half of life: A first empirical approach in Flanders. Tijdschrift voor Gerontologie en Geriatrie, 32, 150 159. 
Schroots, J. J. F. (1996). Theoretical developments in the psychology of aging. The Gerontologist, 36, 742-748.

Thomas, L. E. (2001). The Job hypothesis: Gerotranscendence and life satisfaction among elderly Turkish Muslims. In S. H. McFadden, \& R. C. Atchley (Eds.), Aging and the meaning of time: A multidisciplinary exploration (pp. 207-227). New York: Springer.

Tornstam, L. (1989). Gero-transcendence: A reformulation of the disengagement theory. Aging, 1, 55-63.

Tornstam, L. (1992). The Quo Vadis of gerontology: On the scientific paradigm of gerontology. The Gerontologist, 32, 318-326.

Tornstam, L. (1994). Gerotranscendence: A theoretical and empirical exploration. In L. Thomas, \& S. A. Eisenhandler (Eds.), Aging and the religious dimension (pp. $203-$ 225). Greenwood: Westport.

Tornstam, L. (1996a). Caring for the elderly. Introducing the theory of gerotranscendence as a supplementary frame of reference for caring for the elderly. Scandinavian Journal of Caring Sciences, 10, 144-150.

Tornstam, L. (1996b). Gerotranscendence: A theory about maturing into old age. Journal of Aging and Identity, 1, 37-50.

Tornstam, L. (1997a). Gerotranscendence in a broad cross-sectional perspective. Journal of Aging and Identity, 2, 17-36.

Tornstam, L. (1997b). Gerotranscendence: The contemplative dimension of aging. Journal of Aging Studies, 11, 143-154.

Tornstam, L. (1997c). Life crises and gerotranscendence. Journal of Aging and Identity, 2, 117-131.

Tornstam, L. (1999a). Gerotranscendence and the functions of reminiscence. Journal of Aging and Identity, 4, 155-166.

Tornstam, L. (1999b). Late-life transcendence: A new developmental perspective on aging. In L. E. Thomas, \& S. A. Eisenhandler (Eds.), Religion, belief and spirituality in late life (pp. 178-201). New York: Springer.

Tornstam, L., \& Törnqvist, M. (2000). Nursing staff's interpretations of "gerotranscendental behavior" in the elderly. Journal of Aging and Identity, 5, 15-29. Wadensten, B., \& Carlsson, M. (2001). A qualitative study of nursing staff members' interpretations of signs of gerotranscendence. Journal of Advanced Nursing, 36, 635642. 
Wadensten, B., \& Carlsson, M. (2003). Theory-driven guidelines for practical care of older people, based on the theory of gerotranscendence. Journal of Advanced Nursing, $41,462-470$.

Wong, P. T. P., Reker, G. T., \& Gesser, G. (1994). The Death Attitude Profile-

Revised (DAP-R): A multidimensional measure of attitudes towards death. In. R. A. Niemeyer (Ed.), Death anxiety handbook: Research, instrumentation, and application (pp. 121-148). Washington: Taylor \& Francis. 


\section{Tables}

Table 1

Items of the Gerotranscendence Scale and their Factor Loads, Organized by Subscale

$\underline{\text { Factors }}$

Item

I $\quad$ II III

\section{Subscale I: Transcendent connection}

3. I feel connected with the entire universe.

$\begin{array}{lll}.72 & .00 & .12\end{array}$

4. I feel that I am a part of everything alive.

$.70-.02 \quad .28$

21. Being at peace and philosophizing by myself is important for my well-being.

$\begin{array}{lll}.64 & .17 & -.07\end{array}$

16. My personality has both female and male components.

$\begin{array}{lll}.61 & .13 & -.30\end{array}$

2. Knowing that life on earth will continue is more important than my individual life.

$.51 \quad .03 \quad .08$

15. I find it easy to laugh at myself.

$.47-.15-.20$

22. I find it easy to see what's right and wrong in other people's behavior.

$\begin{array}{lll}.42 & .14 & .27\end{array}$

17. I like meetings with new people.

$.39-.03 \quad .25$

1. I feel a strong connection with earlier generations.

$\begin{array}{lll}.32 & .18 & .28\end{array}$

\section{Subscale II: Anxiety and uncertainty}

8. Sometimes I feel like I live in the past and present simultaneously.

7. It seems unfair that I must die sometime when life on earth just continues. $\quad \begin{array}{ccc}-.13 & .59 & .20\end{array}$

5. I am afraid of death.

12. My life feels chaotic and disrupted.

$.14 \quad .56-.30$

23. I am often afraid of asking stupid questions and embarrassing myself in front of others.

24. For me, having a high material standard is among the most important things in life right now.

6. Some things that happen in life can't be explained by logic and science and need to be left unresolved.

\section{Subscale III: Active involvement}


20. I find it easy to give other people good advice.

$.22 \quad .06 \quad .58$

19. I need something going on all the time in order to feel good.

$\begin{array}{lll}-.14 & .22 & .57\end{array}$

13. I take myself very seriously.

$.20 \quad .08 \quad .56$

25. For me, being active in my work and other things is among the most important.

$\begin{array}{lll}.09 & .08 & .56\end{array}$

18. I like to be by myself better than being with others.

$\begin{array}{lll}.13 & .21 & -.33\end{array}$

\section{Remaining items}

9. I can feel a strong presence of people who are elsewhere.

$\begin{array}{lll}.45 & .36 & .09\end{array}$

10. Genealogy research seems interesting to me.

$.27 \quad .17 \quad .09$

11. The life I have lived has coherence and meaning.

$.45-.28 \quad .43$

14. To be honest, I must say that I am the most important thing in the world. $\quad \begin{array}{lll}.14 & .27 & .27\end{array}$ 
Table 2

Range, Mean, Standard Deviation, and Internal Consistency of Relevant (Sub)scales

$\begin{array}{lllll}\text { (Sub)scale } & \text { Range } & \text { M } & \text { SD } & \alpha\end{array}$

\section{Gerotranscendence Scale}

Transcendent connection

$0-45$

25.11

6.70

.73

Anxiety and uncertainty

$0-35$

12.54

5.15

.60

Active involvement

$0-25$

15.10

3.55

.51

\section{Death Attitude Profile Revised}

Avoidance of death

Fear of death

Escaping acceptance of death

Neutral acceptance of death

Approaching acceptance of death
$-15-15$

$-6-6$

$-15-15$

$-12-12$

$-30-30$
$-2.55$

6.78

.87

$-0.85$

2.96

.71

$-0.26$

6.42

.82

6.44

3.93

.71

$-1.64$

13.16

.91

Post-Critical Belief Scale

Orthodoxy

$-24-24$

$-7.95$

9.54

.88

External critique

$-27-27$

$-3.51$

9.52

.86

Relativism

$-24-24$

7.62

6.40

.75

Second naiveté

$-24-24$

6.52

7.52

.80

\section{Spiritual Orientation}

Spiritual beliefs

$-18-18$

6.13

5.42

.79

Spiritual practices

8-32

11.03

3.76

.83

Spirituality (subjective)

$1-5$

3.07

1.04

\section{Moral Judgement Test}

Moral consistency

$0-100$

17.83

15.82

St 1: Punishment and Obedience

$-8-8$

$-2.98$

5.96

St 2: Individual Instrumental

Purpose and Exchange

$-8-8$

$-1.26$

5.19

St 3: Mutual Interpersonal Expectat.,

Relationships and Conformity

$-8-8$

$-1.05$

5.10

St 4: Social System and Conscience

Maintenance

$-8-8$

0.76

4.12 
St 5: Prior Rights and Social Contract

St 6: Universal Ethical Principles

$-8-8$

$-8-8$
3.24

2.50

3.49

Note. $\mathrm{St}=$ Stage 
Table 3

Correlations between Gerotranscendence Subscales and Other Variables

\begin{tabular}{llll}
\hline Sub)scales & TC & AU & AI \\
\hline Age & $-.11^{*}$ & $-.14^{* *}$ & $.15^{* *}$
\end{tabular}

Death Attitude Profile Revised

Avoidance of death

$\begin{array}{lll}-.32 * * * & .16 * * * & .17 * * * \\ -.06 & .41 * * * & .17 * * * \\ -.07 & .14 * * & .07 \\ .21 * * * & .00 & -.09 * \\ .11 * & .17 * * * & .24 * * *\end{array}$

Post-Critical Belief Scale

Orthodoxy

$\begin{array}{rll}-.22 * * * & .04 & .27 * * * \\ -.18 * * * & -.01 & -.18 * * * \\ .28 * * * & .05 & -.08 \\ .22 * * * & .12 * & .24 * * *\end{array}$

\section{Spiritual Orientation}

Spiritual beliefs

Spiritual practices

$\begin{array}{ccc}.46 * * * & .13 * * & .12 * * \\ .44 * * & -.01 & -.01\end{array}$

\section{Moral Judgement Test}

Moral consistency

$\begin{array}{rrr}.20 * * * & .06 & -.05 \\ -.17 * * * & .01 & .08\end{array}$

St 1: Punishment and Obedience

$-.12 * \quad .07$

.09

and Exchange

.07

St 3: Mutual Interpersonal Expectations,

Relationships and Conformity

$-.12 * \quad .07$

$.21 * * *$

St 4: Social System and Conscience

Maintenance

$\begin{array}{llr}-.03 & .09 * & .07 \\ .16 * * * & .09 & -.03 \\ .16 * * * & .08 & .05\end{array}$

St 5: Prior Rights and Social Contract 
$* p<.05, * * p<.01, * * * p<.001$

Note. $\mathrm{TC}=$ Transcendent connection; $\mathrm{AU}=$ Anxiety and uncertainty; $\mathrm{AI}=$ Active involvement; $\mathrm{St}=$ Stage 


\section{Table 4}

Significant Betas in the Regression of Gerotranscendence Scores on Different Predictor Variables

Predictors

$\beta \quad \mathrm{t}$

\section{Transcendent Connection}

Spiritual beliefs

$\begin{array}{cc}0.310^{* * *} & 6.037 \\ 0.191^{* * *} & 4.042 \\ 0.137^{* *} & 2.626 \\ -0.131^{*} & -2.521 \\ 0.30 & \end{array}$

Spiritual practices

Religion and faith: relativism

\section{t}

Avoidance of death

Adjusted $\mathrm{R}^{2}$

0.30

\section{Anxiety and Uncertainty}

Fear of death

$\begin{array}{cc}0.390^{* * *} & 7.816 \\ 0.155^{* *} & 2.619 \\ 0.128^{*} & 2.345 \\ -0.193^{* * *} & -3.883 \\ 0.21 & \end{array}$

Adj. $R^{2}$

0.2

\section{Active Involvement}

Moral development: stage 3

$\begin{array}{cc}0.243^{* * *} & 4.052 \\ 0.105^{*} & 2.002 \\ -0.166^{*} & -2.419 \\ 0.13 & \end{array}$

$* p<.05,{ }^{* *} p<.01, * * * p<.001$ 